\title{
Thinking Caused by Migration: Multidimensional Relationship between New Subculture and Mobile Media
}

\author{
Ma Jun \\ Weinan Normal University, Newspaper Community, Weinan, Shaanxi, 714099
}

Keywords: Media Migration, New Subculture Scene, Mobile Media, Breeding and Inspiration

\begin{abstract}
The migration of the media has changed the physical form of the information production and communication to a certain extent, thus affecting the audience's psychology and way of receiving information. Have a common interest in the audience because of small new media facilities and more easy to form a circle, the formation of new sub culture groups, such as the barrage of video sites, video broadcast platform, gaming game platform, LGBT community etc.. The main mobile media as a medium of migration, it spawned a variety of sub culture scene, the influence of sub cultural texts and forms, to continue dialogue sub culture and mainstream culture and sub culture, new scenes of prosperity, and will attract media attention, mobile community spread attention element issues, pay attention to the subculture of economy.
\end{abstract}

\section{Introduction}

"Although the" sub culture "(subculture) this concept is the first by the United States in mid 1940s with a sociologist, but before this, the Sociology Department of University of Chicago has carried out the related research work, not only in the concept of a name." After the enrichment and perfection of the Bermingham school and the "subculture" has become a hot research issue in the academic circles. Wu Changqing in the "media analysis of the function of network media in youth culture forming in the role of" contemporary youth culture in the formation of a horse; the evaluation "new media and youth subculture" to a paper analyzes the network technology to promote the media on youth subculture turned; Cheng Pengcheng "influence of subculture of youth under the mass media" the paper focuses on the youth sub culture how to influence the choice of media; Zhang Shizhuo's "the social network of youth sub culture groups and cultural reconstruction" a paper on the social networking site as the representative of the new media on the youth sub culture construction and communication of changes. The research on subculture has gradually expanded with the continuous updating of the media [1-2]. Global Web Index "2016 third quarter social networking report" shows that: users visit the mobile social networking platform on average for 1.77 hours, and generally have more than 6 social accounts. The user data on social platform massive and precise information push the monopoly of information consumption with most of the scene audience, when the mobile media and social networking platform has become the main channel for people and social contact, social network, broadcast application, interest community and other new media platform rise [3]. "The strength of a new medium will lead to the emergence of a new civilization." The migration of 43 media has brought about new scenes of sub cultural tribes. In these new scenes, the social effects are highlighted, and the media consumption is also moving from "mass" to "interest oriented differentiation and individuation". What are the main manifestations of these new scenes? In this scenario, between sub culture and mobile media is how to become the main and foothold of this study.

\section{The New Scene of the Subculture Tribes Formed by the Migration of Media}

The essence of subculture is scene culture: a group of people gathered in the same scene for some interest or commonality, then interact on more dimensions, and form sub culture circles based on their common culture. Therefore, when the media migration causes the change of the audience's attention, and then attracts the audiences with a common interest, forming a niche culture scene, a 
new sub culture scene based on the new media is generated.

\subsection{Barrage video website: two sub culture}

As the barrage between "otaku" minority culture overnight into public view, which is behind the sub culture of the dominant culture of social penetration. The so-called barrage, that is, cannon like comments flooded the screen. The review is the main body in the video of the barrage, and the video is only the position. The barrage culture can gather large numbers of fans and form new subculture scenes, mainly based on two reasons: first, interest resonance is just needed. "The B station is a small public product," said Chen Rui, executive director of the B station, the earliest use of barrage technology in China [4]. "The cultural background of the barrage is because of loneliness. It comes from the loneliness of the lovers." The barrage network provides the user with a wonderful scene of mutual interest and interaction. Second, the circle and culture are the core competitiveness. Compared with ordinary video sites, B stations prefer to locate themselves as young people's cultural brand and lifestyle. On this platform, the circle based on common interests is the energy ring to maintain platform loyalty. Therefore, the accumulation of users in B stations has always relied on word of mouth, and the opening of new users is extremely cautious. It is necessary to complete a difficult "two dimensional test paper". Tribal scenes based on common interests allow users to have a strong cultural resonance.

\subsection{Video direct platform: sharing subculture}

Meerket, Ocho, screening, six rooms... In 2015, the big wave video broadcast platform was out and out, and it also created a number of live wild people. Any user can broadcast the webcam toward the scene to live in real time, and share the sub culture in the live broadcast process, becoming a new subculture scene generated by the mobile media. In September 2015, a social live App called "17-Your-Life" (s-Moments) was launched in the first few days of the United States and China's App Store free list. Only 3 months online, it created a series of hot miracles. Broadcast platform is hot, actually cut a user's psychology: first, to share to Wang strong users, which meet their love of the "sun" psychology; secondly, onlookers "Voyeur" to further promote the development of such applications; third, live content segmentation, but also to meet the interest subdivision needs of users. "17" App has been on the shelf due to the content of live broadcast, but the video live platform has brewed a new "sharing" sub culture. In the future, everything can be broadcasted, and form community interaction with the form of live broadcast, thus creating the community economy [5].

\subsection{Games gaming platform: Gaming subculture}

Electronic athletics is a very broad concept, the traditional sense of the gaming game types include FPS (first person shooter), RST (RTs), sports car, and in recent years the rise of MOBA games, such as "hero alliance" "DOTA2" "king of glory" etc.. According to the latest data show that in 2016 the global Gaming Association, e-sports game player has reached 1 billion 680 million people, in recent years, the annual output value of the market and the gaming derivatives industry growth rate of nearly 7\%, forecast in 2017 nearly $\$ 90$ billion of the huge business opportunities. Gaming as a sub culture is also a kind of interest through the alliance, game player role playing in the virtual world to form a circle, in this circle, there is a set of rules and standards and different social reality. A top player in the game may not be outstanding in daily life, but in the game bar, he is the "great God" that is worshipped. This is a new social relationship and culture, and the relationship between players in the virtual world does not usually extend to the line, but this social relationship is highly sticky. Players are willing to buy better equipment for higher social status, or to build stronger alliances. The gaming platform also showing powder absorbing power sub culture "based on the platform of interest".

\subsection{LGBT community: sexual subcultures}

LGBT (Lesbians, Gays, Bisexuals, Transgender acronym) is internationally known for lesbian, gay, bisexual, transgender and other sub cultural groups. The social network and consumer platform, 
are based on the interests and needs of the LGBT subculture, are growing up and forming an unparalleled "Rainbow economy" [6]. The prosperity of LGBT community stems from objective conditions, which makes gay people have sustainable social needs all their life. Besides, the social occasions and conditions behind gay line are far behind those of heterosexual. The convenience of mobile media naturally makes up for the social gap of homosexuals. In the LGBT platform, users can make friends, sharing, and psychological and physiological based on just need to interact with high frequency, and form their own social circle, thus forming a sexual subcultures community.

Now a large extent and mobile media are related dimensions continues to surge a new scene of sub culture, provide media mobile media scene breeding migration caused by heat for the new scene of sub culture, it will construct, and stimulate the birth of a new scene sub culture of birth, but offers great opportunities a new scene sub culture formation of sub culture groups of mobile media development.

\section{The Breeding of Media Migration to the New Subculture Scene}

\subsection{The mobile media spawn a variety of subcultural scenes}

Mobile media to further break through time and space, again breaking the constraints of time and space of cultural reproduction, it can be more convenient to help the subculture people interaction, sharing ideas, the construction of community, the Bermingham school case study compared to those seen in the factory area, the light head Tsai, hippie and punk, is largely reduced the sub culture of the rapid formation of tribal threshold. For example, the emergence of "know you" community provides an excellent interactive place for subculture people. At this time, any sub culture's problems, ideas and opinions can be exchanged online at any time. People can talk about "Japan July", will also discuss the characteristics of "two dimension crowd", there are "kill Matea culture is how the formation of" questions [7]. "As the British scholar Bill Aus said in this youth sub culture and media pointed out:" the fans on behalf of a media consumer experience into new text production in culture, new culture and new culture came into being. "'

\subsection{The influence of mobile media on subcultural texts and forms}

The mobile media not only affects the existence and dissemination of the subcultural diversity, but also affects the form and the expressive function of the subcultural text. The new technology and products win wider and independent writing space for sub culture, providing various supports for their free expression, communication and entertainment. For example, the application of mobile video "small coffee show", the user only needs to follow the subtitle "the mouth", it can generate comic creative and funny video, also share a key to social networks, compared to ten years ago "become fashionable for a time after the boys" funny video, "small coffee show" and other video applications will undoubtedly provide the production and dissemination of support more efficient and convenient for subculture. At the same time, the new media technology also has a great influence on the expression style and aesthetic significance of subculture. Embezzlement, parody, KUSO and collage, all the meaning reconstruction or digestion behavior is far from profound. Everyone is a master of subculture.

\subsection{The continuous dialogue between the subculture and the mainstream culture by the mobile media}

Subculture and mainstream culture continue to talk and blend in the new media environment. Subculture in history appears as a mainstream cultural antagonist. However, with the opening up of society, sub culture which once caused "moral panic" is gradually accepted by society and become a part of social main body culture. In this process, the mobile media has further broken the "high wall" between the mainstream culture and the subculture, and the "bilateral dialogues" are becoming more and more frequent. For example, the circle of friends have a heat transfer research literature "from the mainstream to the $\mathrm{AB}$ station: 80, 90, 00 sub cultural attributes and succession of Internet investment strategy", in this paper, a large number of popular science sub culture concept 
of things, such as two yuan, three yuan, two, AGG, ABH, a barrage of disease wait, let mainstream public opinion on the subculture from fuzzy to progressive cognitive [8]. Especially the polymerization mobile media and social networking platform, everyone can be their own work and life whenever and wherever possible, tourism scene to share, the share will cause between mainstream culture and sub cultures, communication, learning and transformation, so that some sub culture can be accepted by the public, into the mainstream culture and sub culture community members will be absorbed by the mainstream culture of their enlightening content. It should be pointed out that it is not characteristic of sub culture and mainstream culture "confrontation" disappear, youth sub culture group will use their new media technology advantage, build a protective wall, through technical barriers to escape or active isolation culture clamp.

\section{The Enlightenment of the Subculture Community to the Mobile Media}

The emergence of new tribal subculture will converge more large-scale subculture community members, sub cultural issues which will have diversified, and sub culture of social economy, as a mobile media of gestation and birth of these new sub culture scene to maximize the power of mobile media community spread, with the correct attitude to "hug" the new tribal culture.

\subsection{Thinking awakening: attention to community communication}

The dissemination of traditional media information is mainly based on the "point to face" non -differentiated public distribution. However, in the era of mobile media, this extensive dissemination has been unable to meet the needs of subcultural tribal members with strong ethnic identity. At the same time, through the study of the transmission path of the mobile media, it is found that the community communication has great explosive force and potential of communication. According to penguin Zhi cool data, from May 12, 2015 to July 21st, the social discussions about the popular TV drama flower thousand bones exploded in a short time, and formed a high-speed growth trend. And even serious issues are widely spread in the community. For example, in the 196 day of A share's storm, along with the growth of Shanghai stock index, stock group's news volume increases synchronously. When stock price is unstable, the activity of stock group also fluctuates. The data show that between July 1, 2015 and July 20th, the activity of related communities increased steadily after the game was launched, and the visits of such interest tribes showed greater fluctuations by the impact of topic operation and time. Sub culture as a kind of community culture, community has a strong identity for culture, coupled with the sense of community members and high activity, as a sub culture began to spread information, forwarding will immediately triggered tribe members, then along the chains formed viral. At the same time, mobile media also need to excavate demand on the basis of invading communities and satisfying needs, and build communities through their own advantages, so as to create demand and give full play to the "Dandelion effect" of social communication.

\subsection{Content awakening: focusing on multiple issues}

The uncertainty of the existence of one yuan culture is clearly demonstrated by the variability and liquidity. A new scene sub cultural prosperity, showing "innovation and cultural construction of Qianxi force generation, and through the practice of sub culture, to snatch the right to speak their own cultural position, and look forward to the discussions in their own way and society. In order to meet the increasingly subculture needs, we need to break the myth of "mass" and "minority" cultural divide with the new media represented by mobile media and pay attention to multiple sub culture topics. For example: Tencent news personalized reading product "express", in the line will open more personalized channel outside the mainstream news perspective, including the "gaming" "space" and "divination" and "delicacy" and other channels, the user can customize the menu page and in the news, a channel for "marking" "comment" interaction. Further, the mobile media now need to explore experience as the center of the youth sub culture content and how products are made of high quality, high sense of substitution, to, to replace today on sub culture common shallow label understanding, so as to help the mobile media to attract more millennials to users, and they are 
the main mobile media consumption in the future [9]. At this point, VICE has been a great success. Since its establishment, VICE has put the focus of its reports on the life of non-mainstream cultural and social marginal people. Its reporting always aims at giving users a sense of conflict and letting people see a completely different life culture from their lives. An editor of VICE said, "we just want to use" millennial generation "thinking logic and language to tell them exactly where the world is, and we want the new generation of audiences to be interested in the world. 70 in recent years, VICE has begun to force video content. The topic is still focused on the world subculture or subculture, and it has a great attraction among young people.

\subsection{Industrial awakening: attention to subcultural economy}

The crowd in sub culture is a group gathered because of a common interest in some niche lifestyle or aesthetic preference. They are also easy to pay for something that fits their group ideas. In other words, there are "idolatry" and "emotional consumption" in subcultural groups, such as the peripheral products of consumer subculture. Penguin Zhi cool visited 11996 respondents. The results showed that more than 1/5 users had had consumption behavior in the network community, and the proportion reached $17.2 \%$. Community based interactions, questions and answers and reviews are more likely to establish dynamic assessments of the quality of goods and services, thus building a consumer stickiness and credibility. Located in Tokyo Taitung District, Japan Akihabara, is home to Japanese otaku culture important, a large number of model toy stores, animation products and theme Cafe co-exist here. Here is the first Japanese female idol group AKB48. The origin of AKB48 fans brought amazing fans economy effect, the combination lock "otaku" consumer market, the economic downturn in Japan under the background of the creation of a new business model and business value, also known as the "economics of plaid skirt". Therefore, subculture is regarded as one of the "most commercial value" areas by the contemporary commercial society. Global famous brands, such as Harley moto and Pepsi, have been using subculture in their brand marketing strategies. It can be said that the awakening of subculture has brought a new space for commercial value, and through the mining of more refined subcultures.

If the transformation of media from "lead and fire" to "light and electricity" has solved the "pain point" of audiences in information dissemination, then the transformation of media from light and electricity to number and network is to satisfy the audience's "cool spot". From "pain point" to "refreshing point", it is not only the transformation of media form, but also the upgrading of the audience experience. Mobile media is attracting and aggregating a group of young people with minority interest or fringe interest by using its fast, convenient and all-weather way of communication, and then guides and creates subculture communities. The prosperity of subculture community will stimulate the production of sub culture community to a certain extent. Therefore, follow-up research can turn the perspective from "cultural orientation" to "organizational orientation", and investigate the rules of community economy triggered by media migration. The media industry should also play the role of the community economy and other issues, extending the follow-up study of the subculture community.

\section{References}

[1] Sun S L, Borkhüffer T, Yeoh B S A. Mobility, migration and new media: Manoeuvring through physical, digital and liminal spaces [J]. New Media \& Society, 2016, 18(10): págs. 2147-2154.

[2] Faith B. Review: Migration and New Media: Transnational Families and Polymedia (Mirca Madianou and Daniel Miller) [J]. Mobile Media \& Communication, 2012, 3(2): 289- 290.

[3] Ellen Helsper. Migration and New Media: Transnational Families and Polymedia [J]. Social Science Diliman, 2013, 35(6):782-783.

[4] Team P E. Migration and New Media: Transnational Families and Polymedia by Mirca Madianou and Daniel Miller [J]. Journal of Children \& Media, 2012, 7(2):273-277.

[5] Lorenzana J A. Book review: Mirca Madianou and Daniel Miller, Migration and new media: 
Transnational families and polymedia [J]. Mobile Media \& Communication, 2013, 3(2):289-290.

[6] Mao J X, Politics S O, University A N, et al. Subculture Research and Its Paradigm Shift in the Context of New Media [J]. Journal of Anhui Polytechnic University, 2016.

[7] Lippert D N, Wilkins J A. Glia maturation factor gamma regulates the migration and adherence of human T lymphocytes [J]. Bmc Immunology, 2012, 13(1):21.

[8] Lášticová B. New media, social capital and transnational migration: Slovaks in the UK [J]. Human Affairs, 2014, 24(4):406-422.

[9] Sun S L. At the crossroads of change -New media and migration in Asia [M]// Routledge Handbook of New Media in Asia. 2015. 